\title{
Octopamine Regulates Sleep in Drosophila through Protein Kinase A-Dependent Mechanisms
}

\author{
Amanda Crocker and Amita Sehgal \\ Department of Neuroscience, Howard Hughes Medical Institute, University of Pennsylvania, Philadelphia, Pennsylvania 19104
}

\begin{abstract}
Sleep is a fundamental process, but its regulation and function are still not well understood. The Drosophila model for sleep provides a powerful system to address the genetic and molecular mechanisms underlying sleep and wakefulness. Here we show that a Drosophila biogenic amine, octopamine, is a potent wake-promoting signal. Mutations in the octopamine biosynthesis pathway produced a phenotype of increased sleep, which was restored to wild-type levels by pharmacological treatment with octopamine. Moreover, electrical silencing of octopamine-producing cells decreased wakefulness, whereas excitation of these neurons promoted wakefulness. Because protein kinase A (PKA) is a putative target of octopamine signaling and is also implicated in Drosophila sleep, we investigated its role in the effects of octopamine on sleep. We found that decreased PKA activity in neurons rendered flies insensitive to the wake-promoting effects of octopamine. However, this effect of PKA was not exerted in the mushroom bodies, a site previously associated with PKA action on sleep. These studies identify a novel pathway that regulates sleep in Drosophila.
\end{abstract}

Key words: Drosophila; octopamine; sleep; locomotion; norepinephrine; biogenic amine; arousal

\section{Introduction}

Sleep is a core process that spans genetically diverse eukaryotes from mammals to arthropods (Tobler, 2005). Disrupting sleep in any of these organisms is detrimental to their performance, memory, and health (Rechtschaffen, 1998). Extreme loss of sleep can even lead to death (Shaw et al., 2002). Thus, it must serve a very important function. Its conservation over evolution supports this claim for another reason: the need to sleep must outweigh selection pressure to eliminate it as a risk to predation. However, the function of sleep is unknown, and the molecular regulation underlying it is poorly understood.

Sleep can be monitored through electroencephalograms and electromyograms, but, when such electrophysiological recordings are technically difficult, as in the case of Drosophila, it is monitored through analysis of behavior. Drosophila show a sleep state characterized by changes in position, increased arousal threshold, and periods of inactivity that can last several hours (Hendricks et al., 2000; Shaw et al., 2000). Although little is known about the regulation of this sleep state, effects of some neurotransmitters have been described. Thus, GABA and serotonin promote sleep, the latter by acting through the $5-\mathrm{HT}_{1 \mathrm{~A}}$ receptor expressed in the mushroom body (MB) (Yuan et al., 2006).

\footnotetext{
Received July 2, 2008; revised Aug. 1, 2008; accepted Aug. 1, 2008.

This work was supported in part by a program project grant from the National Institutes on Aging. A.C. was supported by a training grant to the Center for Sleep and Respiratory Neurobiology at the University of Pennsylvania and by a National Research Service Award from the National Institute of Mental Health. We thank Drs. Jay Hirsh, Ed Kravitz, Trudi Schupbach, Ben White, and Bill Joiner for providing flies used in this study. We also thank Bill Joiner, Kyunghee Koh, Max Kelz, Eliot Friedman, and Natalia Nedelsky for critical reading of this manuscript and K. Luu for assisting with animal maintenance.

Correspondence should be addressed to Dr. Amita Sehgal, Department of Neuroscience, Stemmler Hall, Room 232, 36th and Hamilton Walk, University of Pennsylvania, Philadelphia, PA 19104. E-mail: amita@mail.med.upenn.edu.

D01:10.1523/JNEUROSCI.3072-08a.2008

Copyright $\odot 2008$ Society for Neuroscience $\quad$ 0270-6474/08/289377-09\$15.00/0
}

The only arousal-promoting signal identified in Drosophila is dopamine (Andretic et al., 2005; Kume et al., 2005).

In mammals, dopamine and norepinephrine are associated with states of arousal (Aston-Jones and Bloom, 1981). However, results regarding the effects of norepinephrine on total sleep and wake amounts have been mixed (Hunsley and Palmiter, 2003; Ouyang et al., 2004), in part because of differences in experimental protocols and also perhaps attributable to the effects of norepinephrine manipulation on dopamine levels (Schank et al., 2006). The insect equivalent of norepinephrine, octopamine, is synthesized and regulated through pathways that are distinct from those that produce dopamine. However, although octopamine is known to play a role in memory formation, larval locomotion, wing beating, ovulation, and aggression (Roeder, 2005), it has not been examined for effects on sleep. Here we demonstrate a novel role for octopamine in the regulation of sleep and wake in Drosophila. Feeding octopamine to flies leads to a protein kinase A (PKA)-dependent decrease in total sleep, whereas removal of octopamine from the food is followed by a sleep rebound. In addition, flies mutant for octopamine show an increase in total sleep, which can be restored to control levels with the administration of octopamine. We show that electrical excitation of octopamine-producing cells decreases total sleep, whereas electrical silencing of these cells increases sleep. Other parameters of sleep such as sleep latency and arousal threshold are also altered. Last, we demonstrate an activity-promoting role for the octopamine precursor tyramine, which is independent of the effects of octopamine.

\section{Materials and Methods}

Fly strains used. Wild-type fly strains included $w ; R C 1 ; R C 1$ (isogenized chromosome 1 from the $w^{1118}$ stock; isogenized chromosomes 2 and 3 from the RC1 strain) and $w^{1118}$, Canton S, Iso31 (Isogenic $w^{1118}$ strain). 
Octopamine production mutants included $\mathrm{Tdc} 2^{\mathrm{RO} 54}$ (tyrosine decarboxylase 2 mutant) and $T \beta H^{\mathrm{nM} 18} / F M 7$ (tyramine $\beta$ hydroxylase mutant). Gal4 lines included Tdc2-Gal4 (neuronal Tdc2 expression pattern), Tdc1-Gal4 (non-neuronal Tdc1 expression pattern), ElavGeneSwitch (pan-neuronal expression during adulthood), and MBSwitch (mushroom body-specific expression during adulthood). Upstream activating sequence (UAS) lines included UAS-B16B (NaChBac) (bacterial $\mathrm{Na}^{+}$ channel), UAS-Kir2.1(inward rectifying $\mathrm{K}^{+}$channel), UAS-BDK33 (PKAr) (Drosophila inhibitory subunit of PKA with mutated cAMP binding site), $U A S-T d c 2$, and $U A S-T d c 1$. The following lines were ordered from the Bloomington Stock Center: Tdc2-Gal4 (9313), Tdc1-Gal4 (9312), UAS-NaChBac (9466), UAS-Tdc2 (9315), UAS-Tdc1 (9314), UAS-GFPnls (7032), and Iso31 (5905). UAS-Kir2.1 and UAS-B16B were a gift from Dr. B. White (National Institutes of Health, Bethesda, MD). ElavGeneSwitch (Osterwalder et al., 2001), MBSwitch (Mao et al., 2004), and UAS-BDK33 (Rodan et al., 2002) were used previously in the laboratory (Hendricks et al., 2001; Joiner et al., 2006). The wild-type isogenic line $w ; R C 1 ; R C 1$ was a gift from W. Joiner (University of Pennsylvania, Philadelphia, PA). Tdc2 $2^{\mathrm{RO} 54}$ lines and $w^{1118}$ background line were a gift from Dr. G. Schupbach (Princeton University, Princeton, NJ) and Dr. J. Hirsh (University of Virginia, Charlottesville, VA). The $T \beta H^{\mathrm{nM} 18} / F M 7$, $T \beta H^{m 6} / F M 7$, and Canton $S$ background control were a gift from Dr. E. Kravitz (Harvard University, Boston, MA).

All Gal4 and UAS lines were outcrossed seven times into the $w ; R C 1$; $R C 1$ or Iso31 background. The $w ; R C 1 ; R C 1$ background was chosen for the Tdc2-Gal4-expressing Kir2.1 because it shows lower levels of nighttime sleep (supplemental Table 1, available at www.jneurosci.org as supplemental material) and thus affords the potential to avoid a ceiling effect.

Sleep analysis. Sleep analysis was performed as described previously (Joiner et al., 2006). All flies were kept on a $12 \mathrm{~h}$ light/dark (LD) cycle at $25^{\circ} \mathrm{C}$ schedule unless otherwise noted. Female and male flies $4-8 \mathrm{~d}$ old were placed in $65 \times 5 \mathrm{~mm}$ tubes containing $5 \%$ sucrose and $2 \%$ agar and entrained for 24-36 h before the sleep recording. Baseline sleep was determined by monitoring activity for at least $3 \mathrm{~d}$ with no disruptions in an LD cycle. Locomotor activity was monitored using the DAMS/Trikinetics system as described previously (Joiner et al., 2006). Sleep was defined as a 5 min bout of inactivity as described previously (Shaw, 2003; Joiner et al., 2006). Latency to sleep was defined as the time in minutes from the moment lights were turned off to the first bout of sleep. Sleep consolidation scores were generated based on the amount of fragmentation seen in sleep, as measured by brief awakenings and the length of sleep bouts.

Arousal threshold. Arousal threshold was measured at three times of the night ( $2 \mathrm{~h}$ after lights off, $6 \mathrm{~h}$ after lights off, and $10 \mathrm{~h}$ after lights off). Increasing levels of mechanical stimulation were applied to determine the minimum stimulus for arousal. The levels were then labeled weak, medium, and strong, with weak being the lowest level of stimulation and strong being the maximum. Animals were scored based on their response to these three levels (Hendricks et al., 2000).

Feeding octopamine and tyramine. Wild-type ( $w ; R C 1 ; R C 1, I s o 31) \mathrm{fe-}$ male animals were loaded into monitors as described above and given $24-36 \mathrm{~h}$ to acclimate. One day of baseline data were collected, and then, at the lights-on transition, the flies were transferred either to tubes containing $5 \%$ sucrose $/ 2 \%$ agar plus $10 \mathrm{mg} / \mathrm{ml}$ octopamine or onto sucrose/ agar alone. Octopamine, administered at $10 \mathrm{mg} / \mathrm{ml}$ orally, was shown previously to be optimal for rescuing egg laying (Monastirioti et al., 1996). A dose-response curve of Iso31 flies on octopamine is shown in supplemental Figure $3 A$ (available at www.jneurosci.org as supplemental material). The animals were left for $3 \mathrm{~d}$ on or off octopamine and removed at the lights-on transition. Rebound was determined and analyzed as described previously for sleep deprivation (Joiner et al., 2006). The males were examined in the same manner; however, $10 \mathrm{mg} / \mathrm{ml} \mathrm{oc-}$ topamine was fatal for them over $3 \mathrm{~d}$ so the octopamine concentration was reduced to $5 \mathrm{mg} / \mathrm{ml}$ (data not shown). Other concentrations of octopamine were tested, but $10 \mathrm{mg} / \mathrm{ml}$ was found to be the optimal amount for $3 \mathrm{~d}$ for wild-type females (supplemental Fig. $3 A$, available at www. jneurosci.org as supplemental material). A blue food assay was performed as described (Edgecomb et al., 1994) to ensure that the animals were eating the food (data not shown). Because of the lethality seen with $10 \mathrm{mg} / \mathrm{ml}$ octopamine, the $T \beta H^{\mathrm{nm} 18}$ females and controls were placed on $7.5 \mathrm{mg} / \mathrm{ml}$ octopamine.

Tyramine was also fed to wild-type flies. Similar to what was seen with octopamine, tyramine at higher concentrations produced increased lethality so wild-type male flies were fed $5 \mathrm{mg} / \mathrm{ml}$ tyramine in $5 \%$ sucrose $/ 2 \%$ agar. Females were placed on $10 \mathrm{mg} / \mathrm{ml}$ tyramine in $5 \%$ sucrose $/ 2 \%$ agar. We tested other amounts of tyramine and determined that $10 \mathrm{mg} / \mathrm{ml}$ was the optimal concentration (data not shown).

Mianserin was also used to address octopamine signaling. Based on the work of Maqueira et al. (2005), who used this compound to block cAMP increases attributable to octopamine in vitro, it was used at $0.2 \mathrm{mg} / \mathrm{ml}$. All mianserin experiments were done with Iso31 control flies. Following the same protocol outlined above for octopamine, we placed flies on mianserin alone, mianserin plus $10 \mathrm{mg} / \mathrm{ml}$ octopamine, control food, or control plus $10 \mathrm{mg} / \mathrm{ml}$ octopamine.

Hydroxyurea analysis. Ablation of mushroom bodies with hydroxyurea $(\mathrm{HU})$ was performed as described previously (de Belle and Heisenberg, 1994). First-instar larvae of Iso31 flies were collected and placed on either a yeast paste and water mixture or a yeast paste and $50 \mathrm{mg} / \mathrm{ml} \mathrm{HU}$ mixture for $4 \mathrm{~h}$ at $25^{\circ} \mathrm{C}$. They were then washed with water and placed in regular food vials until adulthood. At $4-8 \mathrm{~d}$ after eclosion, animals were loaded into monitor tubes as described above. They were given $3 \mathrm{~d}$ of acclimation and then transferred onto $7.5 \mathrm{mg} / \mathrm{ml}$ octopamine, because high lethality was observed at $10 \mathrm{mg} / \mathrm{ml}$. After $3 \mathrm{~d}$, the animals were then transferred back onto normal 5\% sucrose agar tubes. Sleep analysis was then performed as described above. After the completion of the sleep analysis, fly heads were dissected in $4 \%$ paraformaldehyde and fixed for $30 \mathrm{~min}$, mounted on slides, and analyzed for loss of the $\alpha$ and $\beta$ lobes of mushroom bodies.

PKA inhibition studies. For PKA inhibition studies, we crossed the ElavGeneSwitch transgene into UAS-BDK33 flies. Octopamine at 10 $\mathrm{mg} / \mathrm{ml}$ was used as described above. Because the GeneSwitch construct can be turned on during adulthood using the drug RU486 (11 $\beta$-(4dimethylamino)phenyl-17 $\beta$-hydroxy-17-(1-propynyl)estra-4,9-dien-3one), we placed half the animals on $5 \%$ sucrose $/ 2 \%$ agar tubes containing either $500 \mu \mathrm{M}$ RU486 dissolved in ethanol or ethanol alone (1\%) for $3 \mathrm{~d}$ Half of each group was then transferred to octopamine-containing food with either $5 \%$ sucrose/2\% agar plus $500 \mu \mathrm{M}$ RU 486 plus octopamine or $5 \%$ sucrose/2\% agar plus ethanol (1\%) plus octopamine. Both groups were also simultaneously fed $10 \mathrm{mg} / \mathrm{ml}$ octopamine for $3 \mathrm{~d}$. At the lights-on transition at the end of this period, animals were transferred off of octopamine onto $5 \%$ sucrose $/ 2 \%$ agar containing either $500 \mu \mathrm{M}$ RU486 or ethanol (1\%). Sleep analysis was performed as described above.

Statistics. To compare multiple groups, two-way ANOVA was used to determine significance for total sleep, nighttime sleep, daytime sleep, sleep bout number for both day and night, and latency to sleep. For non-Gaussian distributed data, we used the Kruskal-Wallis test; this included sleep bout length (daytime and nighttime), consolidation score, activity per waking minute, and peak activity. Statistical significance is denoted by asterisks: ${ }^{\star} p \leq 0.01,{ }^{* *} p \leq .001$, and ${ }^{\star * *} p \leq .0001$.

\section{Results}

\section{Mutants with reduced octopamine have increased sleep}

To address a role for octopamine and its precursor tyramine in Drosophila sleep, we analyzed two known genes that affect biosynthesis of these amines (Monastirioti et al., 1996; Cole et al., 2005; Certel et al., 2007). As shown in the flow diagram in Figure $1 A$, the $T d c 2$ enzyme synthesizes tyramine (precursor to octopamine) from tyrosine; thus, its disruption results in low levels of octopamine and tyramine (Cole et al., 2005). In contrast, $T \beta H$ synthesizes octopamine from tyramine, and therefore its loss reduces octopamine but increases tyramine levels 10-fold (Fig. 1A) (Monastirioti et al., 1996). Because synthesis of both amines requires $T d c 2$, the cellular distribution of $T d c 2$ should reflect cells that potentially produce both tyramine and octopamine. We determined the expression pattern of $T d c 2$ by using the well known 
A.

\section{Tyrosine

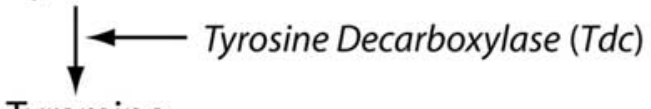 \\ Tyramine

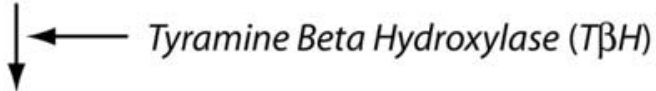 \\ Octopamine}

B.

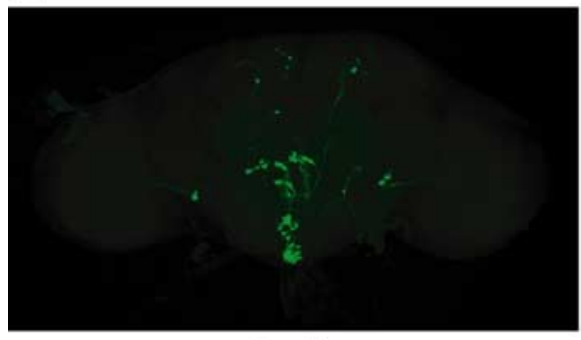

Brain

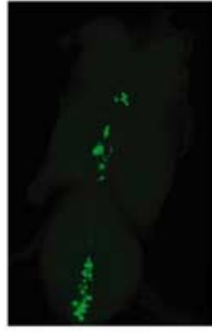

Thorax
Figure 1. The octopamine biosynthesis pathway and its distribution in the fly brain. $\boldsymbol{A}$, Octopamine and tyramine are derivatives of tyrosine. Tyrosine is converted to tyramine by $T d c$. Tyramine is then converted to octopamine by $T \beta H$. $\boldsymbol{B}$, Expression pattern of the $T d \mathrm{c} 2-\mathrm{Gal} 4$ line as visualized with a GFP reporter. Octopamine is produced in a subset of neurons in the brain and thoracic ganglion, respectively. Expression was characterized by crossing $T d c 2-G$ al 4 with nuclear UAS-GFPnls.

UAS-Gal4 binary system to express green fluorescent protein (GFP) under the control of the Tdc2 promoter (Fig. $1 B$ ). Expression of GFP was seen in discrete unilateral subsets of cells located along the ventral medial line of the brain, as well as in discrete bilateral clusters of cells in the lateral protocerebrum region and surrounding the esophagus cavity.

We then assayed sleep in flies mutant for each of the two genes in the octopamine biosynthesis pathway. Baseline sleep levels were examined in flies carrying a point mutation in the $T d c$ gene $\left(T d c 2^{\mathrm{RO} 54}\right)$ or a lesion, created by imprecise excision of a $\mathrm{P}$ transposable element, in the $T \beta H$ gene $\left(T \beta H^{\mathrm{nm} 18}\right)$. Under baseline conditions, we found that male and female animals of both mutants displayed increased levels of sleep (Figs. 2A,B, 3A,B). All male data are shown in supplemental Table 1 (available at www. jneurosci.org as supplemental material), whereas female data are depicted in Figures 2-5. The increase in sleep in $\mathrm{Tdc}_{c} 2^{\mathrm{RO} 54}$ and $T \beta H^{\mathrm{nm} 18}$ mutants occurred primarily during the day (Figs. $2 A, B, 3 A, B)$, perhaps because flies are already sleeping maximally during the night. The increase in total sleep was accompanied by a decreased latency to sleep (the time from lights off until the animal's first bout of sleep) in the $T d c 2^{\mathrm{RO} 54}$ mutants (Fig. $2 B$ ), suggesting an increase in homeostatic drive to sleep. The $T \beta H^{\mathrm{nm} 18}$ mutation did not have a significant effect on latency, although there was a slight decrease in males (supplemental Table 1 , available at www.jneurosci.org as supplemental material). The Canton $S$ background strain that the $T \beta H^{\mathrm{nm} 18}$ mutants were crossed into displays rapid onset of sleep compared with other wild-type control lines used in this study (supplemental Table 1, available at www.jneurosci.org as supplemental material), which may occlude any decrease in latency caused by the mutation.

Analysis of sleep architecture indicated that the increase in sleep in $T d c 2^{\mathrm{RO} 54}$ mutants was attributable to an increase in sleep bout number (supplemental Table 2, available at www.jneurosci. org as supplemental material), whereas the increase in $T \beta H^{\mathrm{nm} 18}$
A.

Sleep Profile

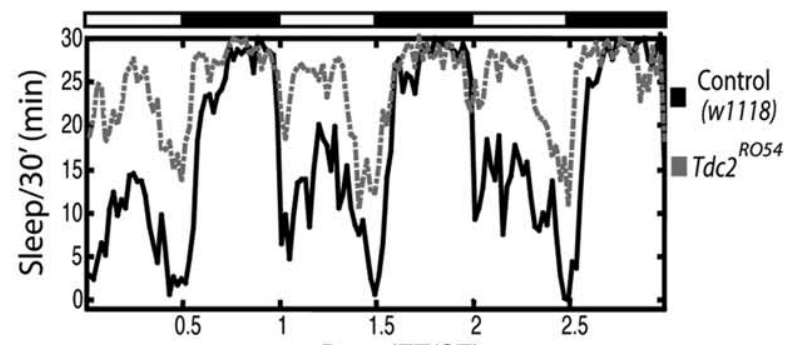

Days (ZT/CT)

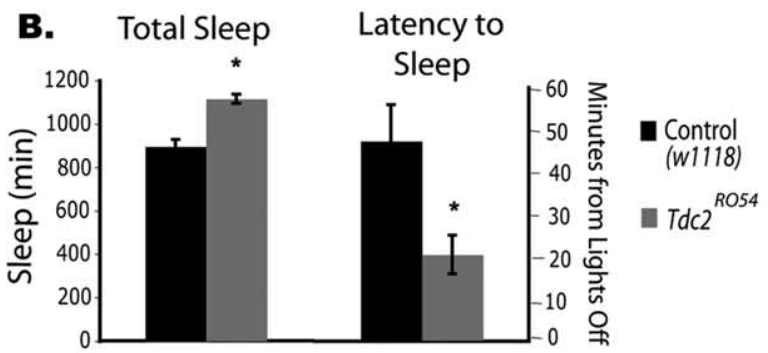

C. Arousal Threshold

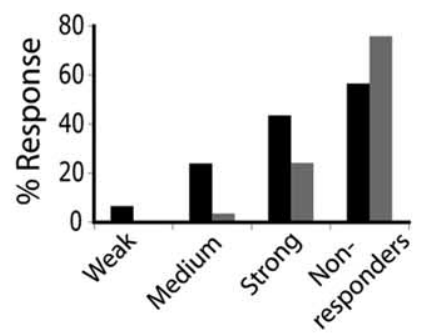

D. Rescue of $T d c 2^{R O 54}$ Sleep

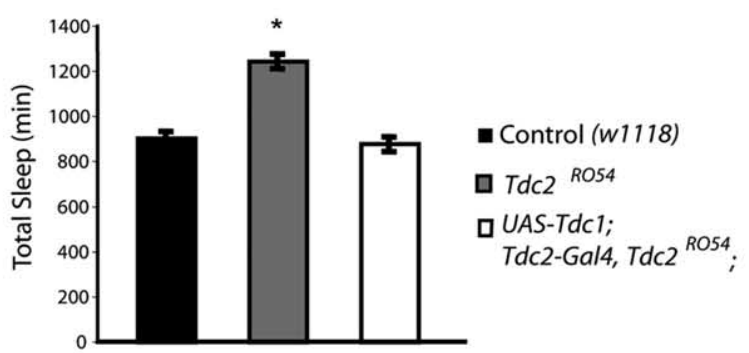

Figure 2. Baseline sleep phenotype of $T d c 2^{R 054}$ mutants, which have decreased levels of octopamine and tyramine. $\boldsymbol{A}$, Three days of baseline sleep recording in $T d c 2$ females. The $T d 2^{\text {R054 }}$ line (gray dashed line) shows significantly more sleep than its control $w^{1118}$ (black solid line). Dark bars and white bars on top indicate nighttime and daytime, respectively. $n=8$ for Tdc ${ }^{\text {R054 }}$ and $w^{1118}$. CT, Circadian time; ZT, Zeitgeber time. $\boldsymbol{B}$, Total sleep is significantly increased in $T d c 2^{\text {R054 }}$ mutant females (mean \pm SEM; Tdc $2^{\text {R054 }}, 1115 \pm 19, n=23 ; w^{1118}$, $895 \pm 32, n=32 ; p \leq 0.0001$, two-way ANOVA). Latency to sleep is significantly lower in $T d c 2^{\text {R054 }}{ }^{0}$ utants (mean \pm SEM; $T d c 2^{\text {R054 }}, 20.6 \pm 4.6, n=23 ; w^{1118}, 47.5 \pm 8.7, n=32$; $p \leq 0.001$, two-way ANOVA). C, Arousal threshold during sleep in the $\operatorname{Tdc} 2^{\mathrm{R} 054}$ mutants. The animals were given three levels of stimulation to determine whether they were arousable. All animals that responded to the first stimulation were also aroused on stronger stimulation. Compared with wild type, the $T d c 2$ mutant line had a higher percentage of flies that did not respond to any of the three levels of stimulation. In addition, fewer $T d c 2^{\mathrm{RO} 54}$ flies responded to the weaker stimuli ( $\left.T d c 2^{\mathrm{R054}}, n=23 ; w^{1118}, n=32\right)$. $\boldsymbol{D}$, Rescue of the baseline sleep phenotype in $T d c 2^{\text {R054 }}$ with expression of the $T d c 1$ gene. Total sleep was quantified, and $T d c 2^{\text {R054 }}$ mutant females were significantly different from both wild-type and rescued animals. There was no significant difference between rescued animals and controls (mean $\pm S E M ; w^{1118}$, $895 \pm 33, n=32 ; T_{d c}{ }^{\text {R054 }}, 1238 \pm 33, n=16 ; p \leq 0.0001 ;$ UAS-Tdc1; Tdc2-Gal4, $\left.T d c 2^{\text {R054 }}, 871 \pm 33 ; n=16\right)$. 

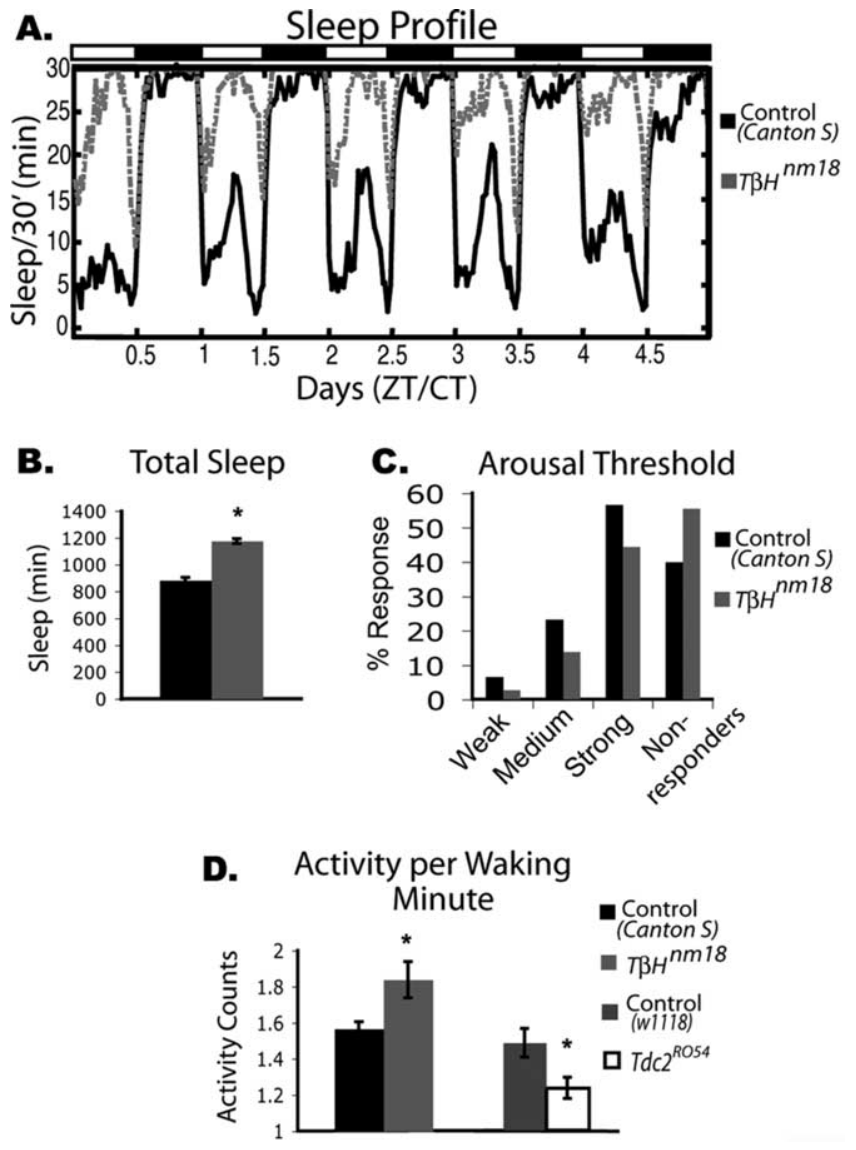

Figure 3. Baseline sleep phenotype of $T \beta H^{\mathrm{nm} 18}$ mutants, which have decreased levels of octopamine and increased levels of tyramine. $A$, Five days of baseline sleep recording in $T \beta H$ females. The $T \beta H^{\mathrm{nm} 18}$ line (gray dashed line) shows significantly more sleep than its control, Canton S (black solid line). Dark bars and white bars on top indicate nighttime and daytime, respectively. Sixteen animals are shown for each group. CT, Circadian time; ZT, Zeitgeber time. $B$, Total sleep is significantly increased in the $T b H^{\text {nm18 }}$ mutants (mean \pm SEM; $T \beta H^{\mathrm{nm} 18}$, $1176 \pm 17, n=46$; (anton S, $884 \pm 20, n=52 ; p \leq 0.0001$, two-way ANOVA). C, Arousal threshold for the $T \beta H^{\mathrm{nm} 18}$ mutants. The animals were given three levels of stimulation to determine whether they were arousable. All animals that responded to the first stimulation were also aroused on stronger stimulation. Compared with wild type, the Tbh mutant line had a higher percentage of flies that did not respond to any of the three levels of stimulation. In addition, fewer $T d c^{\mathrm{R} 054}$ flies responded to the weaker stimuli $\left(T \beta H^{\mathrm{nm} 18}, n=46\right.$; Canton S, $n=52)$. $\boldsymbol{D}$, Activity per waking minute, which quantifies activity during the time the animal is awake, was significantly increased in the $T \beta H^{\mathrm{nm} 18}$ mutants (mean $\pm \mathrm{SEM}$; $T \beta H^{\mathrm{nm} 18}, 1.84 \pm$ 0.13 ; (anton $S, 1.57 \pm 0.05 ; p \leq 0.01$, Kruskal-Wallis test) but significantly decreased in the $T d c 2^{\text {R054 }}$ mutants (mean \pm SEM; $T d c 2^{\text {R054 }}, 1.2 \pm 0.09 ; w^{1118}, 1.5 \pm 0.08 ; p \leq 0.01$, KruskalWallis test).

mutants occurred from an increase in bout length (supplemental Table 2, available at www.jneurosci.org as supplemental material). Because both mutants affect octopamine similarly, this difference in sleep architecture is most likely attributable to differences in levels of tyramine. We also determined the arousal threshold in both mutants by measuring their response to a stimulus of increasing intensity. The arousal threshold during sleep was higher in both sets of mutants than in wild-type flies (Figs. $2 C, 3 C)$. This suggests that these animals are in a deeper state of sleep than their controls.

An increase in sleep could result from the animals being sick and unable to move. To address this possibility, we measured locomotor activity in $T d c 2^{\mathrm{RO} 54}$ and $T \beta H^{\mathrm{nm} 18}$. We found that $T d c 2^{\mathrm{RO} 54}$ and $T \beta H^{\mathrm{nm} 18}$ had peak activity levels that were not significantly different from those of controls (data not shown).
However, the $T \beta H^{\mathrm{nm} 18}$ flies showed significantly increased waking activity (Fig. $3 D$ ), as measured by total activity while awake; despite their increased total sleep time, the $T \beta H^{\mathrm{nm} 18}$ mutants showed a hyperactive phenotype when awake. In contrast, the average rate of movement was significantly decreased in $T d c 2^{\mathrm{RO} 54}$ flies compared with the wild-type controls (Fig. 3D). Because activity in the two mutants is affected in opposite directions, it is unlikely that the increased sleep phenotype of the mutants is secondary to effects on activity. More likely, the loss of octopamine (common to both mutants) underlies the decrease in sleep, whereas differences in tyramine levels account for effects on locomotor activity. In fact, our data are consistent with previously published data indicating that the increased (10-fold) levels of tyramine in the $T \beta H^{\mathrm{nm} 18}$ flies cause an increase in locomotor behavior when awake (Hardie et al., 2007).

It was shown previously that expression of $T d c 1$ (the nonneuronal form of $T d c$ ) in $T d c 2$-producing cells rescues the $T d c 2^{\mathrm{RO} 54}$ mutant locomotor phenotype (Hardie et al., 2007). We found the same to be true for sleep. When $T d c 1$ was expressed in $T d c 2$-producing cells in a $T d c 2^{\mathrm{RO} 54}$ background, we found that we were able to rescue the baseline sleep phenotype (Fig. 2E), as well as sleep architecture and latency to sleep (data not shown).

\section{Altering excitability of octopamine/tyramine-producing cells affects sleep}

If octopamine and/or tyramine are released in the brain to regulate sleep, then blocking or increasing their release should also affect sleep. Thus, we sought to determine whether electrical manipulation of the cells producing tyrosine decarboxylase, which should affect the release of octopamine and tyramine, produces a change in sleep. The Tdc2-Gal4 line mentioned above, which expresses Gal4 in cells producing octopamine and tyramine, was crossed to flies carrying transgenes for ion channels under the control of a UAS element recognized by Gal4 (UAS-NaChBac or UAS-Kir2.1) (Baines et al., 2001; White et al., 2001; Cole et al., 2005; Nitabach et al., 2005). The UAS-NaChBac transgene is derived from a gene encoding a bacterial $\mathrm{Na}^{+}$channel, which has the characteristics of high open probability and low inactivation, thus driving membrane voltage to a more depolarized and easily excited state. Expression of the $\mathrm{Na}^{+}$channel in Tdc2-positive cells resulted in a decrease in sleep of $56.5 \%$, corresponding to a loss of $\sim 346 \mathrm{~min}$ (Fig. $4 A, B$ ). The loss of sleep was specific to the nighttime, with no significant sleep loss during the daytime, which may be indicative of normally high octopamine activity during the day. This hypothesis is consistent with mammalian studies in which the noradrenergic cells of the locus ceruleus fire primarily during the active period (Aston-Jones and Bloom, 1981). We also found a corresponding increase in sleep latency in these flies. They took, on average, 74 min longer to fall asleep after lights off (Fig. $4 \mathrm{~B}$ ). Flies expressing $\mathrm{NaChBac}$ in $\mathrm{Td} c 2$-positive cells also showed a decreased arousal threshold, suggesting that they are easily awakened during the night (Fig. 4C). Bout analysis indicated that nighttime sleep bouts were shorter in duration (supplemental Table 2, available at www.jneurosci.org as supplemental material). In addition, there was a significant increase in daytime bout number (supplemental Table 2, available at www. jneurosci.org as supplemental material), which may reflect increased homeostatic drive resulting from the reduced sleep at night. However, the animals were unable to maintain long sleep bouts even under these conditions.

We also expressed a hyperpolarizing $\mathrm{K}^{+}$channel transgene under the control of the Tdc2-Gal4 driver and found that this produced an increase in total sleep (Fig. 5A,B). Kir2.1 is an in- 

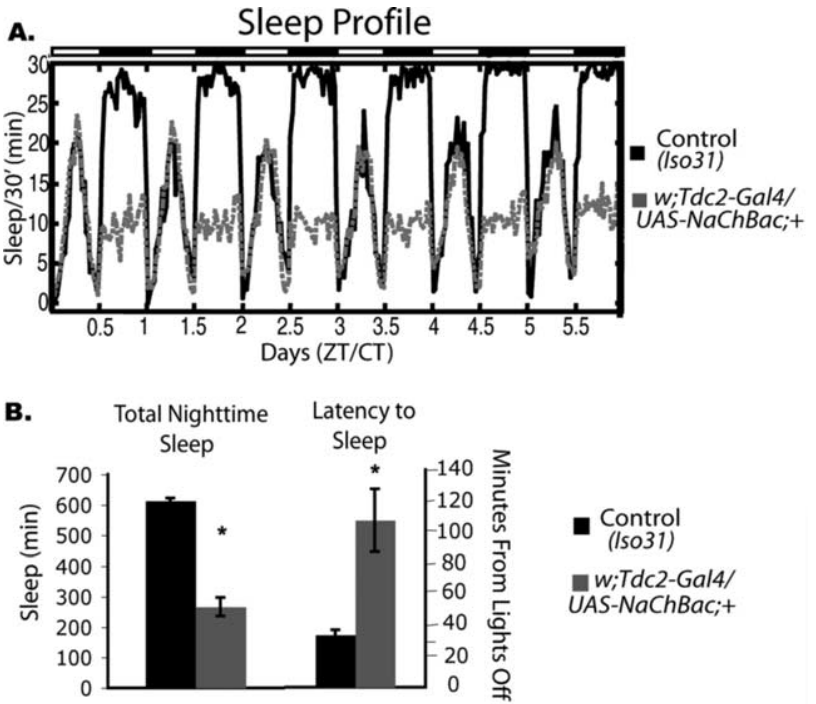

C. Arousal Threshold

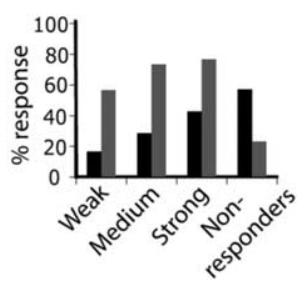

Figure 4. Baseline sleep phenotype produced by depolarizing Tdc2-positive neurons. Female flies carrying a UAS-NaChBac transgene under the control of TDC2-Gal4 were assayed for sleep. $\boldsymbol{A}$, Six days of baseline sleep recording of eight animals each. w;Idc2-Gal4/NaChBac;+ flies (gray dashed line) show significantly less sleep then Iso31 controls (black solid line). Dark bars and white bars indicate nighttime and daytime, respectively. CT, Circadian time; ZT, Zeitgeber time. $\boldsymbol{B}$, Nighttime sleep is significantly decreased in $w ; T d c 2-G a l 4 / N a C h B a c ;+$ flies (mean \pm SEM; $w ; T d c 2-G a l 4 / \mathrm{NaChBac} ;+, 267 \pm 31, n=33 ;$ Iso31, $613 \pm 9, n=58 ; p \leq$ 0.0001, two-way ANOVA). The latency to sleep is significantly longer in w; Tdc2-Gal4/NaChBac; + flies (mean \pm SEM; $w ; T d c 2-G a l 4 / N a C h B a c ;+, 107 \pm 20, n=33 ; / s 031,34 \pm 3, n=$ $58 ; p \leq 0.01$, two-way ANOVA).C, Arousal threshold in the w; Tdc2-Gal4/NaChBac; + flies. The animals were given three levels of stimulation to determine whether they were arousable. All the $w ; T d c 2-G a l 4 / \mathrm{NaChBac} ;+$ flies were more arousable at each stimulation level, and there was a much lower percentage of animals that did not respond at all ( $w ; T d c 2-G a l 4 / \mathrm{NaChBac} ;+$, $n=33 ;$ (so31, $n=58)$.

ward rectifying $\mathrm{K}^{+}$channel that has a high open probability and no inactivation. Expression of this channel hyperpolarizes neurons and decreases membrane resistance, thus making it more difficult for membrane potential to reach threshold for firing action potentials (Baines et al., 2001). Consistent with a previous report, we found that locomotor activity decreased when Tdc2Gal4 was used to express the inward rectifying $\mathrm{K}^{+}$channel (UASKir2.1) (data not shown). Analysis of sleep parameters, however, revealed that it was actually an increase in sleep that accounted for the phenotype (Fig. 5A,B). Flies expressing UAS-Kir2.1 in Tdc2 cells showed, on average, a $174 \mathrm{~min}$ increase in sleep and also displayed changes in several sleep measures such as latency and arousal threshold. These flies also showed a decrease in latency to sleep (Fig. 5B) and an increased arousal threshold during sleep, requiring more stimulation to wake up compared with controls (Fig. 5C). In addition, they showed a trend toward longer bouts of sleep during the night, although the major increase in sleep came from the increased number of sleep bouts during the day (supplemental Table 2, available at www.jneurosci.org as supplemen-
A.

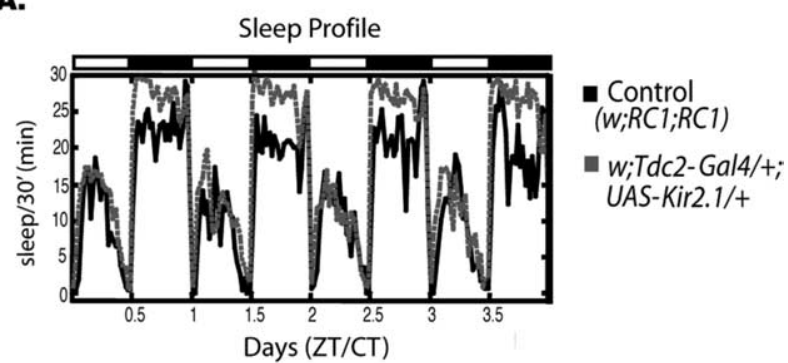

B.

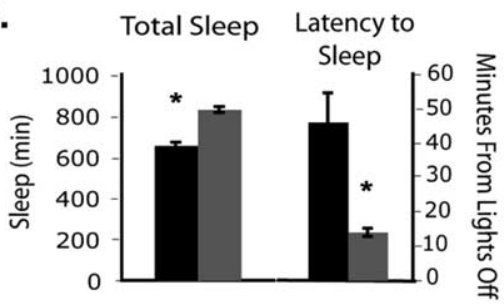

- Control $(w ; R C 1 ; R C 1)$

w;Tdc2-Gal4/+; UAS-Kir2.1/+

C.

$$
\text { Arousal Threshold }
$$

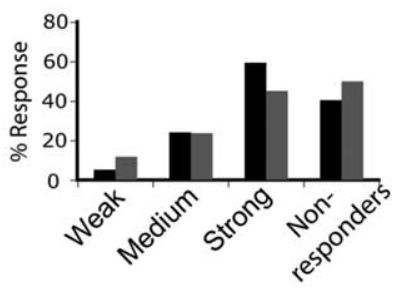

Figure 5. Baseline sleep phenotype produced by hyperpolarizing Tdc2-positive neurons. Female flies carrying a UAS-Kir2. 1 transgene under the control of $T d c 2-G a / 4$ flies were assayed for sleep. A, Four days of baseline sleep recording of 16 animals for each group. w;Idc2-Gal4/ Kir2.1; $R C 1$ flies (gray dashed line) show significantly more sleep then their controls, $w ; R C 1 ; R C 1$ (black solid line). Dark bars and white bars indicate nighttime and daytime, respectively. CT, Circadian time; ZT, Zeitgeber time. B, Total sleep is significantly increased in w;Tdc2-Gal4/ Kir2.1;RC1flies (mean \pm SEM; $w ; T d C 2-G a l 4 / K i r 2.1 ; R C 1,829.19 \pm 14.14, n=47 ; W+; R C 1$; $R C 1,655.35 \pm 15.30, n=47 ; p \leq 0.0001$, two-way ANOVA). The latency to sleep is significantly lower in Tdc2 $\times$ Kir2.1 flies (mean \pm SEM; w;Tdc2-Gal4/Kir2.1;RC1, 13.86 $\pm 1.19, n=$ $47 ; w ; R C 1 ; R C 1,45.68 \pm 8.40, n=47 ; p \leq 0.001$, two-way ANOVA). , Arousal threshold in w; Tdc2-Gal4/Kir2.1;RC1 flies. The animals were given three levels of stimulation to determine whether they were arousable. All animals that responded to the first stimulation were aroused on stronger stimulation. Compared with controls, an increased percentage of w; Tdc2-Gal4/ Kir2.1;RC1 flies did not respond to any of the three levels of stimulation. At the strongest stimulation, more control flies responded than w;TdC2-Gal4/Kir2.1;RC1 flies (w;Tdc2-Gal4/Kir2.1; $R(1, n=47 ; w ; R(1 ; R(1, n=47)$.

tal material). The relative lack of an increase in nighttime sleep length may result from a ceiling effect of sleep at night.

Although sleep levels and architecture are clearly affected in flies expressing sodium or potassium channels in Tdc2 neurons, it is possible that altered activity levels contribute to the overall phenotype. Thus, we also examined peak activity levels and activity while awake. The Tdc2-Gal4 females expressing NaChBac showed significantly lower peak activity (supplemental Table 1, available at www.jneurosci.org as supplemental material) as well as decreased activity while awake compared with the outcrossed background control (mean \pm SEM; w;Tdc2-Gal4/NaChBac; +, $1.7 \pm 0.06$; Iso31, $2.09 \pm 0.06 ; p \leq 0.01$, Kruskal-Wallis test). However, it is unlikely that a decrease in waking activity underlies a reduced sleep phenotype. We also found significantly reduced waking activity in animals expressing the $\mathrm{K}^{+}$channel under the control of the $T d c 2$ driver (supplemental Table 1, available at www.jneurosci.org as supplemental material). This decrease in 
waking activity is similar to the decreased waking activity seen with the $T d c 2^{\mathrm{RO} 54}$ mutant, in which levels of both octopamine and tyramine are low (mean \pm SEM; $w ; T d c 2-G a l 4 / K i r 2.1 ; R C 1$, $2.14 \pm 0.06 ; w ; R C 1 ; R C 1,3.87 \pm 0.97 ; p \leq 0.0001$, Kruskal-Wallis test). Thus, reducing electrical activity in octopamine-producing cells has the same effect on activity and sleep as a mutation $\left(T d c 2^{\text {R054 }}\right)$ that decreases levels of octopamine.

To ensure that the effect on sleep caused by loss of octopamine signaling is specific to neuronal $T d c 2$ and not to a global loss of $T d c$, we made use of a Tdc1-Gal4 driver that is expressed in non-neuronal cells. Expression of the UAS-B16B transgene ( $\mathrm{NaChBac}$ channel) under the control of this driver produced no significant change in sleep (supplemental Fig. 1, available at www.jneurosci.org as supplemental material). Thus, we conclude that the sleep phenotype observed in the $T d c 2^{R 054}$ mutant or produced by manipulations of $T d c$ cells is specific to the neuronal form of $T d c, T d c 2$. Unfortunately, the UAS-Kir2.1 channel proved to be lethal with Tdc1-Gal4.

Given that the NaChBac channel increases excitability of $T d c 2$ cells and thereby presumably stimulates release of octopamine/ tyramine, we asked whether overexpressing $T d c 2$ would have the same effect. As predicted, we found that overexpression of Tdc2 in $T d c 2$-producing cells resulted in a 300 min decrease in nighttime sleep (supplemental Fig. 2, available at www.jneurosci.org as supplemental material). As with the $\mathrm{NaChBac}$ channel, this appears to be a nighttime-specific sleep loss. There was also a decrease in sleep with the overexpression of $T d c 1$ in $T d c 2$ producing cells (data not shown).

\section{Oral administration of octopamine reduces sleep in flies}

Because the $T d c 2^{\mathrm{RO} 54}$ and $T \beta H^{\mathrm{nm} 18}$ mutants change levels of octopamine and tyramine, it is important to dissociate the effects of the two to identify the transmitter responsible for the sleep phenotype. As noted previously, $T d c 2^{\mathrm{RO} 54}$ decreases levels of both tyramine and octopamine, whereas the $T \beta H^{\mathrm{nm} 18}$ decreases octopamine but increases tyramine. To determine whether a change in octopamine is sufficient to regulate sleep, we placed a wild-type isogenic line, Iso31, on octopamine-containing food for $3 \mathrm{~d}$. It was shown previously that animals fed $10 \mathrm{mg} / \mathrm{ml}$ octopamine have increased levels of this neurotransmitter, particularly in the brain (Barron et al., 2007). Supporting this finding, ingested octopamine rescues the egg-laying phenotype displayed by $T \beta H^{\mathrm{nm} 18}$ and $T d c 2^{\mathrm{RO} 54}$ mutants (Monastirioti et al., 1996; McClung and Hirsh, 1999; Cole et al., 2005). We found that flies fed $10 \mathrm{mg} / \mathrm{ml}$ octopamine had $\sim 200 \mathrm{~min}$ less nighttime sleep than control flies maintained on sucrose-agar alone (Fig. 6A) (dose-response curve is shown in supplemental Fig. $3 A$, available at www.jneurosci.org as supplemental material). Thus, similar to the UAS-NaChBac effect, this was a nighttime-specific effect. After the removal of octopamine, these flies showed a corresponding sleep rebound of $\sim 70$ min (mean \pm SEM; control, $289.90 \pm 13.92, n=40 ; 10 \mathrm{mg} / \mathrm{ml}$ octopamine, $367.53 \pm 16.91$; $n=40 ; p \leq 0.001$, two-way ANOVA). In addition to the effect it had on wild-type flies, a lower concentration of orally administered octopamine $(7.5 \mathrm{mg} / \mathrm{ml}$ octopamine) was able to restore the sleep phenotype of the $T \beta H^{\mathrm{nm} 18}$ mutant to control levels (Fig. $6 \mathrm{~B}$ ). This concentration of octopamine produced no significant change in sleep in the Canton $S$ strain, which is the background of the $T \beta H^{\mathrm{nm} 18}$ mutants.

To exclude the possibility that the sleep phenotype was attributable to some nonspecific toxicity associated with octopamine, we attempted to block the effect by inhibiting octopamine signaling. Thus, we coadministered $0.2 \mathrm{mg} / \mathrm{ml}$ mianserin, which acts by

\section{A. Sleep Profile}

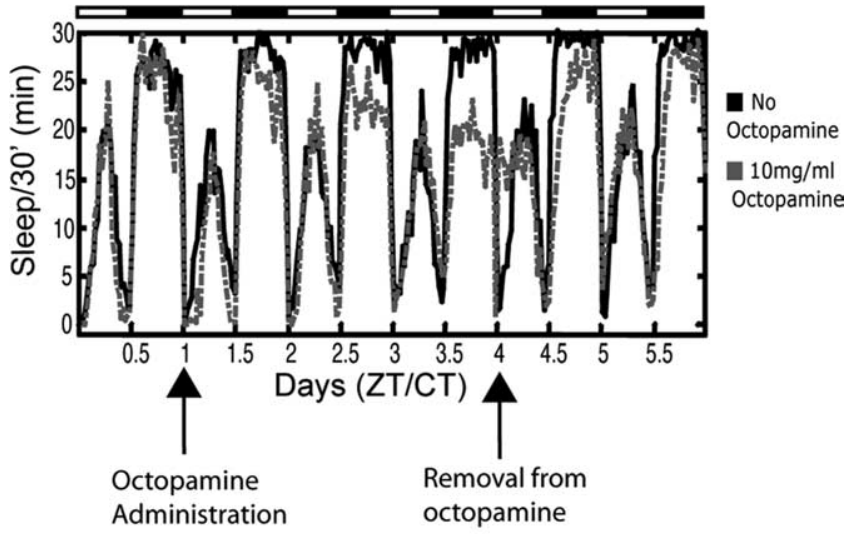

B. Total Sleep

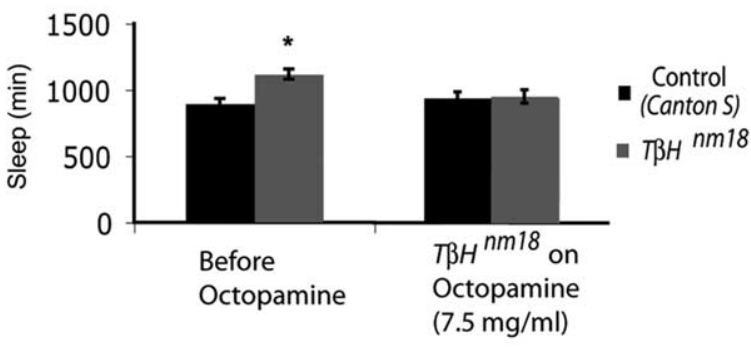

C. Nighttime Sleep with Mianserin

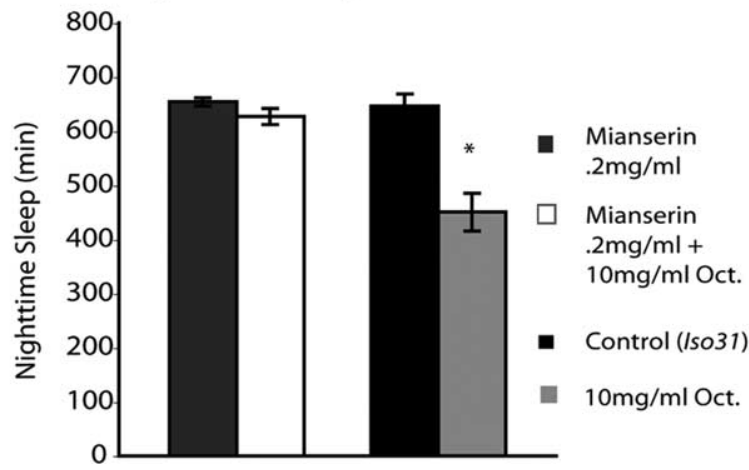

Figure 6. Oral administration of octopamine decreases sleep in $/ 5031$ flies and $T \beta H^{\mathrm{nm} 18}$ mutant flies. Female flies of the 1 so31 strain were treated with octopamine and assayed for sleep. $\boldsymbol{A}$, The sleep profile shows $1 \mathrm{~d}$ of baseline sleep, followed by administration of $10 \mathrm{mg} / \mathrm{ml}$ octopamine (gray dashed line) for $3 \mathrm{~d}$. Octopamine was then removed and sleep was assayed for 2 more days. Control flies (black line) were fed normal food during this time. Arrows indicate the time when food was changed. The data are from 16 animals for each group. There was a significant decrease in nighttime sleep for the $/ s 031$ flies on $10 \mathrm{mg} / \mathrm{ml}$ octopamine (mean \pm SEM; control, $612.04 \pm 8.47, n=40 ; 10 \mathrm{mg} / \mathrm{ml}$ octopamine, $409.33 \pm 19.77, n=40 ; p \leq$ 0.0001, two-way ANOVA). CT, Circadian time; ZT, Zeitgeber time. $B$, Sleep in $T b H^{\mathrm{nm} 18}$ mutant flies is restored to control levels through the administration of octopamine. Before octopamine administration, $T \beta H^{\mathrm{nm} 18}$ flies showed a significant increase in total sleep time; after administration of octopamine, sleep in $T \beta H^{\mathrm{nm} 18}$ flies was not significantly different from that of control (Canton S) flies not on octopamine (Canton S, $796 \pm 55 \mathrm{~min}$; Canton Splus $7.5 \mathrm{mg} / \mathrm{ml}$ octopamine, $792 \pm 54 \mathrm{~min} ; n=16$ for each group). $C$, Coadministration of mianserin blocks the effect of octopamine on nighttime sleep. When $10 \mathrm{mg} / \mathrm{ml}$ octopamine was administered along with $0.2 \mathrm{mg} / \mathrm{ml}$ mianserin, there was no longer a significant drop in nighttime sleep (compare with columns on the right). Sleep in flies treated with mianserin alone was not significantly different from that of controls [mean \pm SEM; mianserin, $654 \pm 8, n=32$; mianserin plus $10 \mathrm{mg} / \mathrm{ml}$ octopamine, $627 \pm 15, n=32$; Is031 (Control), $647 \pm 22, n=32 ; 10 \mathrm{mg} / \mathrm{ml}$ octopamine, $450 \pm 35, n=32 ; p \leq 0.001$, two-way ANOVA] 
inhibiting octopamine-induced cAMP increase (Fig. 6C) (Maqueira et al., 2005). Coadministration of mianserin almost completely blocked the effect of feeding $10 \mathrm{mg} / \mathrm{ml}$ octopamine to flies. This demonstrates that the loss in sleep produced by octopamine feeding is attributable to the ingestion of octopamine itself and not attributable to toxic, nonphysiological effects. In addition, these data suggest that the effects of octopamine on sleep are mediated by $\beta$ receptors.

Wild-type flies fed tyramine did not show significant changes in sleep amount (supplemental Fig. 3B, available at www. jneurosci.org as supplemental material). In addition, neither octopamine nor tyramine produced a significant change in activity while awake (supplemental Fig. 3C, available at www.jneurosci. org as supplemental material).

\section{Octopamine acts via neuronal PKA to decrease sleep}

cAMP-dependent protein kinase (PKA) signaling plays an important role in sleep in Drosophila (Hendricks et al., 2001; Joiner et al., 2006). It is also known to be coupled to some of the octopamine and tyramine G-protein-coupled receptors (Evans and Maqueira, 2005). Indeed, the blocker of octopamine used above inhibits cAMP signaling. To directly address whether the effect of octopamine on sleep is through PKA-dependent pathways, we expressed the regulatory subunit of PKA (PKAr), which inhibits activity of PKA, under the control of an ElavGeneSwitch driver (Osterwalder et al., 2001; Joiner et al., 2006). The use of the ElavGeneSwitch driver allowed us to inducibly express the regulatory subunit in all neurons. We found that expression of PKA $r$ in adult neuronal tissue rendered the flies insensitive to the sleepreducing effects of octopamine (Fig. $7 A$ ), supporting the idea that octopamine is acting through a PKA-dependent pathway to promote arousal.

Because the MB is implicated in the effects of PKA on sleep (Joiner et al., 2006), we sought to determine whether this is also the site of octopamine action on sleep. Thus, we ablated the mushroom bodies with hydroxyurea as described previously (de Belle and Heisenberg, 1994) and then treated these flies with octopamine. The sensitivity to octopamine was intact despite the absence of the MBs (Fig. 7B). As expected, the MB ablation itself reduced sleep, but there was an additional decrease produced by feeding octopamine (Fig. $7 B$ ). The decrease was $87 \mathrm{~min}$, which was comparable with the amount of sleep lost when Iso31 flies were fed $7.5 \mathrm{mg} / \mathrm{ml}$ octopamine $(82 \mathrm{~min})$. To verify that the MBs were ablated, we followed up the behavioral analysis of all flies with anatomical analysis of the brain. All flies that still contained some $\alpha$ and $\beta$ lobes were eliminated from analysis

We also examined the effects of octopamine on flies expressing PKAr under control of an inducible mushroom body GeneSwitch driver (MBSwitch) and found that these flies were still sensitive to octopamine (data not shown). Our inability to block effects of octopamine on sleep by inhibiting PKA signaling in MBs supports the finding that elimination of MBs by hydroxyurea does not block the wake-promoting effects of octopamine.

\section{Discussion}

Biogenic amines play many important roles in mammals, with several having significant effects on sleep-wake states. Thus, dopamine, serotonin, and norepinephrine are all important for regulating states of arousal. We hypothesized that, like its counterparts in mammals, the invertebrate neurotransmitter octopamine would be important for arousal in Drosophila. That prediction was supported by the data reported here. We find that decreases in levels of octopamine increase sleep, whereas increas-
A. Total Nighttime Sleep
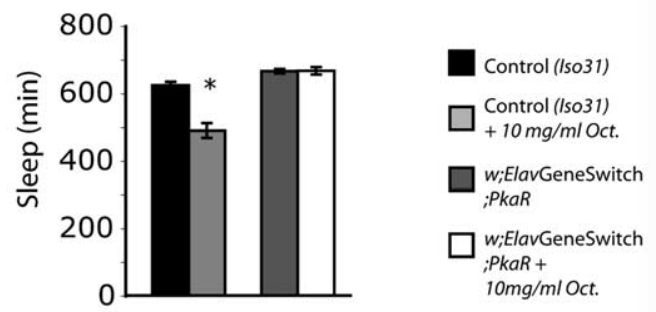

B.

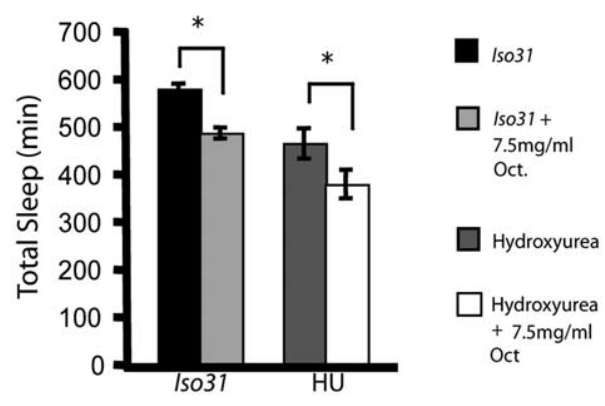

Figure 7. Effects of octopamine are mediated by PKA and are independent of the mushroom body. A, Total nighttime sleep in control (Iso31) and ElavGeneSwitch flies crossed with UASBDK33 (PKAr). The control on $7.5 \mathrm{mg} / \mathrm{ml}$ octopamine shows a significant decrease in nighttime sleep, whereas flies expressing PKAr under the control of ElavGeneSwitch do not show a decrease in sleep in response to octopamine [mean \pm SEM; Control (Iso31), $623 \pm 11, n=24$; control plus octopamine, $489 \pm 22, n=24 ; p \leq 0.001$, two-way ANOVA; ElavGeneSwitch, $665 \pm 7, n=51$; ElavGeneS witch plus octopamine, $667 \pm 11, n=51] \cdot \boldsymbol{B}$, Iso31 flies subjected to hydroxyurea treatment to ablate the mushroom body still show sensitivity to the sleepreducing effects of octopamine. Hydroxyurea-treated flies show a significant decrease in sleep compared with controls; they also show an additional decrease in sleep when placed on 7.5 $\mathrm{mg} / \mathrm{ml}$ octopamine (mean $\pm \mathrm{SEM}$; control, $583 \pm 11, n=24$; control plus $7.5 \mathrm{mg} / \mathrm{ml}$ octopamine, $491 \pm 12, n=24 ; p \leq 0.01$, two-way ANOVA; HU, $469 \pm 32, n=24$; HU plus 7.5 $\mathrm{mg} / \mathrm{ml}$ octopamine, $382 \pm 30, n=22 ; p \leq 0.01$, two-way ANOVA).

ing octopamine causes a decrease in sleep. In addition, although the mammalian data have been contradictory with respect to the role norepinephrine plays in total sleep, we find that octopamine decreases total sleep time. The mammalian data are complicated in part because perturbations of the norepinephrine pathway result in changes in the levels of dopamine (Ouyang et al., 2004). The use of Drosophila allows us to examine specifically the role of octopamine without perturbing dopamine signaling.

By modulating the excitability of octopamine-producing cells, we were able to manipulate the output of these cells. In mammals, one can record from specific cell populations to determine when the cells fire action potentials. Although this assay is difficult to do in flies, we were able to electrically modulate the cells through expression of $\mathrm{K}^{+}$and $\mathrm{Na}^{+}$ion channels. We found that, when octopamine-producing cells were more depolarized (expression of a $\mathrm{Na}^{+}$channel), the animal was awake more and unable to stay asleep, whereas when the cells were hyperpolarized (expression of a $\mathrm{K}^{+}$channel), the animals slept more.

Based primarily on larval crawling assays, octopamine and tyramine were implicated previously in locomotor behavior (O’Dell, 1994; Gong et al., 2004; Saraswati et al., 2004; Scholz, 2005). Specifically, larvae move slower through quadrants when they have decreased octopamine levels (the $T \beta H^{\mathrm{nm} 18}$ and $T d c 2^{\mathrm{RO} 54}$ mutants). More recent work showed that adult $\mathrm{Tdc} 2^{\mathrm{RO} 54}$ flies also have a decrease in locomotor activity attributable to the lack of tyramine (Hardie et al., 2007). Our data show- 
ing differences in activity in the $T d c 2^{\mathrm{RO} 54}$ and the $T \beta H^{\mathrm{nm} 18} \mathrm{mu}-$ tants support the claim that tyramine plays an important role in locomotion. Thus, whereas increased levels of tyramine in $\mathrm{Tbh}$ mutants increase activity, decreased levels in Tdc mutants decrease locomotor activity. However, both mutations increase sleep, which is most likely attributable to the loss of octopamine. In addition to overall sleep, we find that other sleep parameters such as latency to sleep and arousal threshold are affected in flies carrying these mutations. We infer that tyramine plays a role in locomotion, but octopamine specifically affects arousal states.

Studies of other invertebrate species support a role for octopamine in arousal (Corbet, 1991). In fact, octopamine agonists are potential natural pesticides because they cause insect species to "walk off" the leaves (Roeder, 1999). As in Drosophila, changes in octopamine levels affect behavior in honey bees, as demonstrated through feeding and injection of octopamine as well as through analysis of endogenous levels of octopamine. Fussnecker et al. (2006) showed that injections of octopamine promote flying in honeybees. In addition, octopamine and tyramine regulate other behaviors in honeybees such as hive maintenance and foraging (Schulz and Robinson, 1999, 2001; Wagener-Hulme et al., 1999; Barron et al., 2002). Octopamine and tyramine also modulate sensory input in honeybees (Kloppenburg and Erber, 1995; Scheiner et al., 2002). In the locust, octopamine mediates heightened arousal in response to new visual stimuli (Bacon et al., 1995). Bacon et al. found that a specific subset of octopamineproducing neurons in the brain of the locust fires during the presentation of new visual stimuli, causing dishabituation of the descending contralateral movement detector interneuron. Interestingly, application of endogenous octopamine can mimic this state of heightened arousal. Our study suggests that octopamine serves to promote arousal in Drosophila. It is possible that the increased arousal we see with too much octopamine, or decreased arousal with too little, is a result of improper gating of sensory stimuli, but without electrophysiological data we are unable to draw any conclusions. Note also that the $T d c 2$ cells important for sleep and arousal in the fly brain have not been identified yet.

In previous studies, octopamine was fed to flies to rescue or verify a phenotype of the $T \beta H^{\mathrm{nm} 18}$ flies. The ability of octopamine to rescue egg laying in $T \beta H^{\mathrm{nm} 18}$ mutants was assayed in this manner, because $T \beta H^{\mathrm{nm} 18}$ flies are unable to release eggs. Animals were placed on different levels of octopamine, and $10 \mathrm{mg} / \mathrm{ml}$ octopamine over a period of $6 \mathrm{~d}$ provided maximal rescue (Monastirioti et al., 1996). Using the same concentration, we found that a steady increase in octopamine levels led to a decrease in nighttime sleep. Based on the specific effect on nighttime sleep, we speculate that octopamine levels are already high during the daytime, thereby precluding any effects of an increase. This analysis is supported by the $\mathrm{Na}^{+}$channel data in which a significant decrease in total sleep was found only during the nighttime sleep periods. We speculate that, normally, activity of these cells is low at night, and so expression of the $\mathrm{Na}^{+}$channel causes them to fire more and release octopamine at an abnormal time, thereby producing a decrease in sleep. Similar results, indicating nighttimespecific effects, were obtained with overexpression of $T d c 2$. Work in other insects also supports the idea of modulated octopamine release. Pribbenow and Erber (1996) demonstrated that honeybees who are already in a heightened arousal state of antennae scanning do not change scanning frequency in response to octopamine administration, but, in animals scanning at a low frequency, injections of octopamine significantly increase scanning (Pribbenow and Erber, 1996).

Our data suggest that the effects of octopamine are mediated through PKA-dependent signaling. In mammals, there are nine different adrenergic receptors, some of which signal through PKA (Hoffman and Lefkowitz, 1996). The $\alpha 1$ adrenergic receptor is the only receptor associated with a wake-promoting effect in that the agonist methoxamine causes an increase in waking (Hilakivi and Leppävuori, 1984; Monti et al., 1988). However, the antagonist has no effect on total sleep (Benington et al., 1995; Berridge and España, 2000). It is important to note that the $\alpha 1$ receptor in mammals is thought to be coupled to phospholipase $\mathrm{C}$ and $\mathrm{G}_{\mathrm{q}}$ (Ramos and Arnsten, 2007). The $\beta$ adrenergic receptors (which are coupled to cAMP and PKA) probably do not have specific effects on sleep in mammals because, contrary to known effects of norepinephrine, the agonist increases sleep and the antagonist decreases sleep (Monti et al., 1988). Studies in Drosophila may be better able to identify biogenic amine receptors relevant for sleep because of the ease of genetic manipulation. Many G-protein-coupled receptors in Drosophila display activity that allows their bona fide classification as octopamine receptors (Evans and Maqueira, 2005). Our data here suggest that receptors sensitive to mianserin are likely to be involved in regulating fly sleep. Because mianserin inhibits cAMP signaling, these data not only further support a role for PKA but also implicate $\beta$ receptors in octopamine action. We note that none of these receptors is known to display a circadian cycling profile.

Given that PKA was shown previously to regulate sleep in Drosophila, we are starting to see a link between the various molecules that affect Drosophila sleep. Interestingly, however, octopamine does not appear to act through the MBs, a structure known to mediate effects of PKA on sleep and also to express a class of octopamine receptors. Because flies lacking MBs still have substantial amounts of sleep, it is clear that other parts of the fly brain can drive sleep. The current study shows that even PKA can affect sleep in regions outside the MB. Defining the site of action of sleep-regulating molecules such as octopamine should help to identify these other brain regions.

\section{References}

Andretic R, van Swinderen B, Greenspan RJ (2005) Dopaminergic modulation of arousal in Drosophila. Curr Biol 15:1165-1175.

Aston-Jones G, Bloom FE (1981) Activity of norepinephrine-containing locus ceruleus neurons in behaving rats anticipates fluctuations in the sleepwaking cycle. J Neurosci 1:876-886.

Bacon JP, Thompson KS, Stern M (1995) Identified octopaminergic neurons provide an arousal mechanism in the locust brain. J Neurophysiol 74:2739-2743.

Baines RA, Uhler JP, Thompson A, Sweeney ST, Bate M (2001) Altered electrical properties in Drosophila neurons developing without synaptic transmission. J Neurosci 21:1523-1531.

Barron AB, Schulz DJ, Robinson GE (2002) Octopamine modulates responsiveness to foraging-related stimuli in honey bees (Apis mellifera). J Comp Physiol A Neuroethol Sens Neural Behav Physiol 188:603-610.

Barron AB, Maleszka J, Vander Meer RK, Robinson GE, Maleszka R (2007) Comparing injection, feeding and topical application methods for treatment of honeybees with octopamine. J Insect Physiol 53:187-194.

Benington JH, Kodali SK, Heller HC (1995) Stimulation of A1 adenosine receptors mimics the electroencephalographic effects of sleep deprivation. Brain Res 692:79-85.

Berridge CW, España RA (2000) Synergistic sedative effects of noradrenergic alpha(1)- and beta-receptor blockade on forebrain electroencephalographic and behavioral indices. Neuroscience 99:495-505.

Certel SJ, Savella MG, Schlegel DC, Kravitz EA (2007) Modulation of Drosophila male behavioral choice. Proc Natl Acad Sci U S A 104:4706-4711.

Cole SH, Carney GE, McClung CA, Willard SS, Taylor BJ, Hirsh J (2005) Two functional but noncomplementing Drosophila tyrosine decarboxylase genes: distinct roles for neural tyramine and octopamine in female fertility. J Biol Chem 280:14948-14955. 
Corbet SA (1991) A fresh look at the arousal syndrome of insects. Adv Invert Physiol 23:81-116.

de Belle JS, Heisenberg M (1994) Associative odor learning in Drosophila abolished by chemical ablation of mushroom bodies. Science 263:692-695.

Edgecomb RS, Harth CE, Schneiderman AM (1994) Regulation of feeding behavior in adult Drosophila melanogaster varies with feeding regime and nutritional state. J Exp Biol 197:215-235.

Evans PD, Maqueira B (2005) Insect octopamine receptors: a new classification scheme based on studies of cloned Drosophila G-protein coupled receptors. Invert Neurosci 5:111-118.

Fussnecker BL, Smith BH, Mustard JA (2006) Octopamine and tyramine influence the behavioral profile of locomotor activity in the honey bee (Apis mellifera). J Insect Physiol 52:1083-1092.

Gong Z, Son W, Chung YD, Kim J, Shin DW, McClung CA, Lee Y, Lee HW, Chang DJ, Kaang BK, Cho H, Oh U, Hirsh J, Kernan MJ, Kim C (2004) Two interdependent TRPV channel subunits, inactive and Nanchung, mediate hearing in Drosophila. J Neurosci 24:9059-9066.

Hardie SL, Zhang JX, Hirsh J (2007) Trace amines differentially regulate adult locomotor activity, cocaine sensitivity, and female fertility in Drosophila melanogaster. Dev Neurobiol 67:1396-1405.

Hendricks JC, Finn SM, Panckeri KA, Chavkin J, Williams JA, Sehgal A, Pack AI (2000) Rest in Drosophila is a sleep-like state. Neuron 25:129-138.

Hendricks JC, Williams JA, Panckeri K, Kirk D, Tello M, Yin JC, Sehgal A (2001) A non-circadian role for cAMP signaling and CREB activity in Drosophila rest homeostasis. Nat Neurosci 4:1108-1115.

Hilakivi I, Leppävuori A (1984) Effects of methoxamine, and alpha-1 adrenoceptor agonist, and prazosin, an alpha-1 antagonist, on the stages of the sleep-waking cycle in the cat. Acta Physiol Scand 120:363-372.

Hoffman B, Lefkowitz R (1996) Goodman and Gilman's the pharmacological basis of therapeutics, Ed 9. New York: McGraw-Hill Health Professions Division.

Hunsley MS, Palmiter RD (2003) Norepinephrine-deficient mice exhibit normal sleep-wake states but have shorter sleep latency after mild stress and low doses of amphetamine. Sleep 26:521-526.

Joiner WJ, Crocker A, White BH, Sehgal A (2006) Sleep in Drosophila is regulated by adult mushroom bodies. Nature 441:757-760.

Kloppenburg P, Erber J (1995) The modulatory effects of serotonin and octopamine in the visual system of the honey bee (Apis mellifera L.). II. Electrophysiological analysis of motion-sensitive neurons in the lobula. J Comp Physiol 176A:119-129.

Kume K, Kume S, Park SK, Hirsh J, Jackson FR (2005) Dopamine is a regulator of arousal in the fruit fly. J Neurosci 25:7377-7384.

Mao Z, Roman G, Zong L, Davis RL (2004) Pharmacogenetic rescue in time and space of the rutabaga memory impairment by using Gene-Switch. Proc Natl Acad Sci U S A 101:198-203.

Maqueira B, Chatwin H, Evans PD (2005) Identification and characterization of a novel family of Drosophila beta-adrenergic-like octopamine G-protein coupled receptors. J Neurochem 94:547-560.

McClung C, Hirsh J (1999) The trace amine tyramine is essential for sensitization to cocaine in Drosophila. Curr Biol 9:853-860.

Monastirioti M, Linn CE Jr, White K (1996) Characterization of Drosophila tyramine $\beta$-hydroxylase gene and isolation of mutant flies lacking octopamine. J Neurosci 16:3900-3911.

Monti JM, D’Angelo L, Jantos H, Barbeito L, Abó V (1988) Effect of DSP-4, a noradrenergic neurotoxin, on sleep and wakefulness and sensitivity to drugs acting on adrenergic receptors in the rat. Sleep 11:370-377.

Nitabach MN, Sheeba V, Vera DA, Blau J, Holmes TC (2005) Membrane electrical excitability is necessary for the free-running larval Drosophila circadian clock. J Neurobiol 62:1-13.
O'Dell KM (1994) The inactive mutation leads to abnormal experiencedependent courtship modification in male Drosophila melanogaster. Behav Genet 24:381-388.

Osterwalder T, Yoon KS, White BH, Keshishian H (2001) A conditional tissue-specific transgene expression system using inducible GAL4. Proc Natl Acad Sci U S A 98:12596-12601.

Ouyang M, Hellman K, Abel T, Thomas SA (2004) Adrenergic signaling plays a critical role in the maintenance of waking and in the regulation of REM sleep. J Neurophysiol 92:2071-2082.

Pribbenow B, Erber J (1996) Modulation of antennal scanning in the honeybee by sucrose stimuli, serotonin, and octopamine: behavior and electrophysiology. Neurobiol Learn Mem 66:109-120.

Ramos BP, Arnsten AF (2007) Adrenergic pharmacology and cognition: focus on the prefrontal cortex. Pharmacol Ther 113:523-536.

Rechtschaffen A (1998) Current perspectives on the function of sleep. Perspect Biol Med 41:359-390.

Rodan AR, Kiger JA Jr, Heberlein U (2002) Functional dissection of neuroanatomical loci regulating ethanol sensitivity in Drosophila. J Neurosci 22:9490-9501.

Roeder T (1999) Octopamine in invertebrates. Prog Neurobiol 59:533-561.

Roeder T (2005) Tyramine and octopamine: ruling behavior and metabolism. Annu Rev Entomol 50:447-477.

Saraswati S, Fox LE, Soll DR, Wu CF (2004) Tyramine and octopamine have opposite effects on the locomotion of Drosophila larvae. J Neurobiol 58:425-441.

Schank JR, Ventura R, Puglisi-Allegra S, Alcaro A, Cole CD, Liles LC, Seeman P, Weinshenker D (2006) Dopamine beta-hydroxylase knockout mice have alterations in dopamine signaling and are hypersensitive to cocaine. Neuropsychopharmacology 31:2221-2230.

Scheiner R, Plückhahn S, Oney B, Blenau W, Erber J (2002) Behavioural pharmacology of octopamine, tyramine and dopamine in honey bees. Behav Brain Res 136:545-553.

Scholz H (2005) Influence of the biogenic amine tyramine on ethanolinduced behaviors in Drosophila. J Neurobiol 63:199-214.

Schulz DJ, Robinson GE (1999) Biogenic amines and division of labor in honey bee colonies: behaviorally related changes in the antennal lobes and age-related changes in the mushroom bodies. J Comp Physiol A Neuroethol Sens Neural Behav Physiol 184:481-488.

Schulz DJ, Robinson GE (2001) Octopamine influences division of labor in honey bee colonies. J Comp Physiol A Neuroethol Sens Neural Behav Physiol 187:53-61.

Shaw P (2003) Awakening to the behavioral analysis of sleep in Drosophila. J Biol Rhythms 18:4-11.

Shaw PJ, Cirelli C, Greenspan RJ, Tononi G (2000) Correlates of sleep and waking in Drosophila melanogaster. Science 287:1834-1837.

Shaw PJ, Tononi G, Greenspan RJ, Robinson DF (2002) Stress response genes protect against lethal effects of sleep deprivation in Drosophila. Nature 417:287-291.

Tobler I (2005) Phylogeny of sleep regulation. In: Principles and practice of sleep medicine (Kryger MH, Roth T, Dement WC, eds), pp 77-90. Philadelphia: Elsevier/Saunders.

Wagener-Hulme C, Kuehn JC, Schulz DJ, Robinson GE (1999) Biogenic amines and division of labor in honey bee colonies. J Comp Physiol A Neuroethol Sens Neural Behav Physiol 184:471-479.

White BH, Osterwalder TP, Yoon KS, Joiner WJ, Whim MD, Kaczmarek LK, Keshishian H (2001) Targeted attenuation of electrical activity in Drosophila using a genetically modified $\mathrm{K}^{+}$channel. Neuron 31:699-711.

Yuan Q, Joiner WJ, Sehgal A (2006) A sleep-promoting role for the Drosophila serotonin receptor 1A. Curr Biol 16:1051-1062. 